\title{
ERRATUM
}

\section{Tales of collapse}

Alicia Newton

Nature Geoscience 2, 242 (2009); published online: 31 March 2009; corrected after print: 31 March 2009.

In the print version of this News \& Views the page ranges for the two references given in the text were incorrect and should have been: 322-328 and 329-332 respectively. These errors have been corrected in the HTML and PDF versions. 